Int.J. Hum. Soc. Dev. Res.

ISSN (P):2521-1439; ISSN (E):2523-4331

Volume 3, № 1, 2019. 86-101

DOI: $10.30546 / 2523-4331.2019 .3 .1 .86$

\title{
THE SELF DIRECTED LEARNING READINESS (SDLR) METHOD CORRELATION WITH STUDENTS MOTIVATION
}

\section{Saiful BATUBARA}

Universitas Islam Sumatera Utara, Indonesia

\section{Irpan Apandi BATUBARA}

Universitas Islam Sumatera Utara, Indonesia

(C) The Author(s) 2019

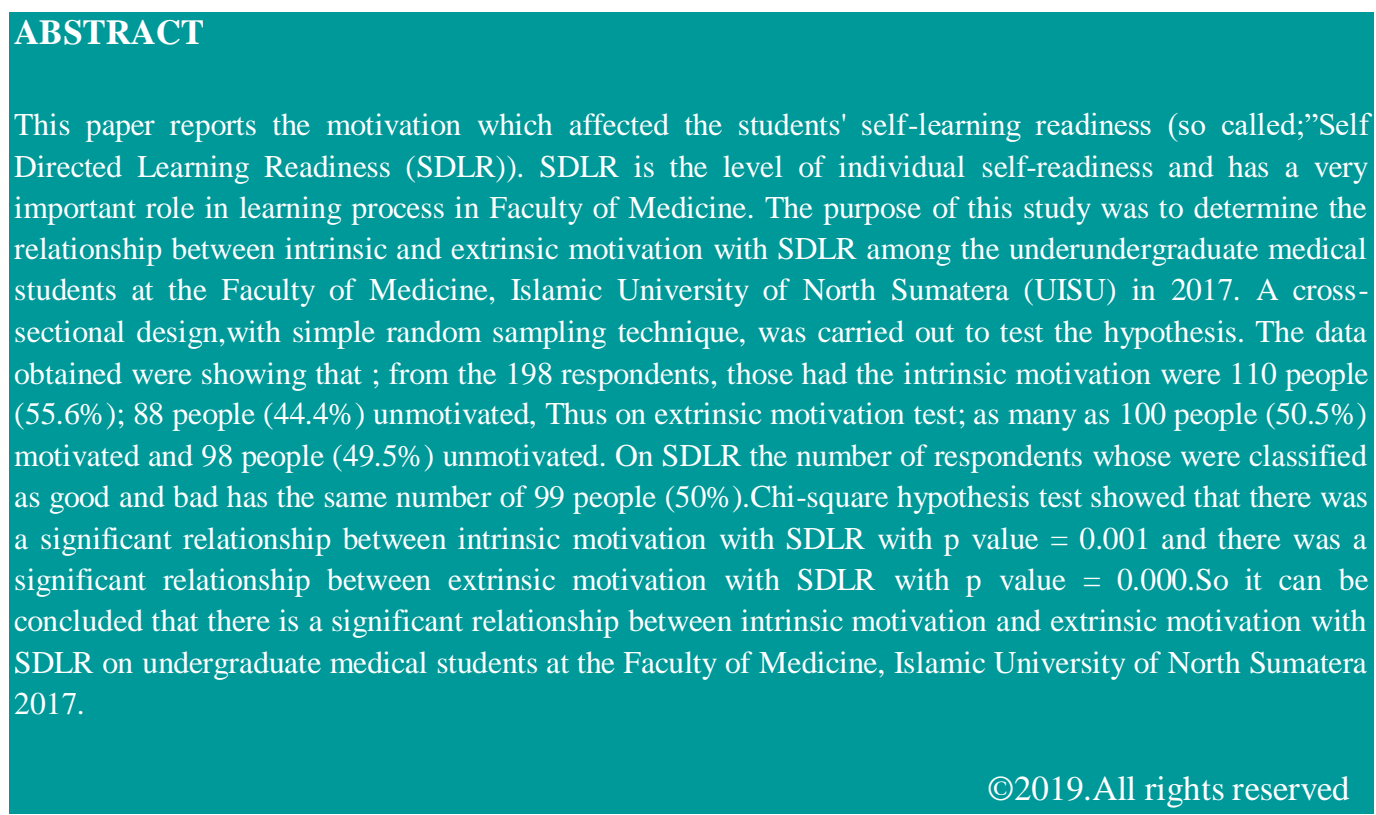

ARTICLE HISTORY

Received: $19 / 11 / 2018$

Accepted: 18/03/2019

Published online: 01/04/2019

\section{KEYWORDS}

Intrinsic motivation; extrinsic motivation; self directed learning readiness. 


\section{Introduction}

Motivation is the driving force by which humans achieve their goals. A mastery goal is defined in term of a focus on learning or mastering a task for self-improvement, development of new skills, or trying to gain understanding (Ningrum \& Matondang, 2017:3637). Brophy in Buckley \& Doyle (2016:1164) explained that in education, motivation is considered a key determinant of learning. It is used to explain the attention and effort students dedicate to particular learning activities. The higher the motivation of a learner the higher the learning outcomes he/she achieved, and vice versa if the motivation to learn of a learner is lower, the lower the learning outcomes will be achieved by him/his. For this reason, part of the role of the teacher is managing learner motivation. In most circumstances, the objective is to increase motivation levels with a view to engendering positive outcomes, such as increased effort, persistence and enhanced performance (Buckley \& Doyle, 2016:1164).

Su \& Cheng (2015:270) argued that a challenging skill level, an individual will develop ability and confidence. The increased perception of competence and selfdetermination creates a state of intrinsic motivation. When an individual is allowed to select activities and materials at optimal levels of difficulty, he or she feels challenged and effectual, feelings which then form the risk-taking learning environment. Feelings of competence and autonomy may motivate a student to learn actively for many hours a week with no additional reward. In contrast Abeysekera \& Dawson (2015:6) state that when a student is motivated by an external reward such as a spesified task being required to get a certain grade in an assignment, they are motivated extrinsically. For example, a student may complete homework as they understand it is important to do so to meet the requirements of the academic qualification necessary to obtain a job within their selected career. In contrast, another student may complete the same homework to adhere to the directions provided by the instructor. The behaviour of both students is influenced by the instrumentality of the homework rather than any inherent enjoyment associated with it. However, the former is derived from personal choice, while the latter is a result of the need to comply with an external authority. Both cases represent extrinsically motivated behaviour, yet differ in their relative autonomy.

Motivation is very important role for the readiness of someone in self-directed learning. Many students complain that his failure to learn because he is less motivated. The readiness of a person in self-learning is referred to as Self Directed Learning Readiness (SDLR) capable of delivering a learner to the stage when he or she can perform or activate the learning system in accordance with his wishes. 
Self-directed learning combines an understanding of what is not known with an understanding of what activities need to be undertaken in order to obtain the needed knowledge. Self-directed learning has been identified as positively correlated with numerous characteristics, including GPA, openness, conscientiousness, emotional stability,extraversion, optimism, career-decidedness, work drive, life satisfaction, and self-actualization (Bartholomew et. al, 2017:4). In 1968, Knowles first proposed the concept of Andragogy illustrating that adults should be equipped with a certain level of self-direction in their learning process, and Knowles commented on the nature of adult learners writing that they "can participate in the diagnosis of their learning needs, the planning and implementation of the learning experiences, and the evaluation of those experiences" (Lai \& Wang, 2012:104). In Self Directed Learning Readiness (SDLR), students are taught to be able to learn with or without the help of others by finding the concept of teaching, learning materials, place of learning and study time from the students themselves. If students are ready to do so then the student can be said to have reached the stage when he was able to perform and activate the learning independently that is commonly called Self Directed Learning (SDL). Basically, every student has a level of Self Directed Learning Readiness (SDLR) that is not the same, therefore it is necessary to evaluate the factors that affect the level of SDLR such as student learning motivation. Self-Directed Learning method itself is also an approach in Problem Based Learning (PBL) system which is commonly known as learning system based on existing problems. This system has been applied in almost all Faculty of Medicine in Indonesia based on Competency Based Curriculum. Until now the value of Competency of graduation in FK -UISU is still low, it shows that the learning done by undergraduate students and doctor's profession is still not maximal. The lack of learning in the Faculty of Medicine using Problem Based Learning (PBL) with Self Directed Learning (SDL) approach is due to the low level of Self Directed Learning Readiness (SDLR).

However, the percentage of students with intrinsic motivation classified motivated in this study is still quite low compared to other studies, such as Roni's research at the Faculty of Medicine, University of Batam in 2016, the number of students with intrinsic motivation is motivated by $69.5 \%$ (146) and students with intrinsic motivation were classified as unmotivated by $30.5 \%$ (64 persons) (Roni, 2016). And Akbar's research at the Faculty of Medicine, University of Gadjah Mada in 2014, the number of students with high intrinsic motivation is $64.5 \%$ (291 persons), moderate $34.4 \%$ (155 persons) and relatively low $1.1 \%$ (5 persons) (Akbar, 2014).

Therefore, the researchers were interested to examine the factors that can influence SDLR, in this case intrinsic and extrinsic motivation. Then this study will analyze the correlation among intrinsic and extrinsic motivation with SDLR undergraduate student of FK (FK) of Islamic University of North Sumatera University (UISU) in 2017. 


\section{Formulation of the Problem}

Based on the background, The research question can be formulated as follows: How is the relationship among intrinsic and extrinsic motivation with Self Directed Learning Readiness (SDLR) on medical undergraduate students of FK UISU in 2017 ?

\section{The Objective of the Study}

To identify the correlation of intrinsic and extrinsic motivation with Self Directed Learning Readiness (SDLR) of undergraduate program student of FK-UISU in 2017.

\section{Research Method}

This research was conducted in the cross-sectional approach. Nursalam in Irawati \& Yuliani (2014:7) state that cross-sectional approach is a type of research approach that emphasizes the time of measurement or observation of independent and dependent variable data only once, at one time The study was crried out from July 2017 until January 2018. The place of research will be conducted in FK of UISU. Population in this research is all student of the faculty of batch 2014, 2015, 2016, and 2017 which amounted to 289 people. The sample size was 198 respondents. The sample in this research was taken with simple random sampling technique.

In this study the instrument used is a questionnaire that has been tested for validity and reliability by previous researchers. For intrinsic motivation, questionnaire reliability coefficient value was Chronbach's Alpha $=0.858$, extrinsic motivation questionnaire's reliability coefficient value of Chronbach's Alpha $=0.937$ and Self Directed Learning Readiness Score (SDLRS) value question reliability coefficient of Chronbach's Alpha = 0 .

The data analysis was done in several techniques, i.e:

\section{Descriptive Statistics}

According to Aluy et. al (2017), the descriptive statistics is a method related to the collection and presentation of a data cluster so that it will provide useful information. Descriptive statistics in this study was to provide information characteristics of research variables, especially regarding the mean or average and standard deviation or standard deviation. The mean or the mean for the quantitative data 
is to sum all the data divided by the amount of data available. Mean is also the most commonly used way of measuring the central value of a data distribution.

Standard deviation or standard deviation is a measure of deviation derived from the square root of the average number of squares deviation between each value with the mean (Aluy et. al, 2017). Descriptive statistics aims to explain or describe the characteristics of each research variable. Each independent variable and dependent one are displayed with descriptive statistics to generate the distribution and percentage of each variable. In this research the data that has been processed is displayed in the form of tables of each variable.

\section{Hypothesis Test}

Hypothesis testing is conducted on two variables that are suspected to be correlated. To know the relationship between Intrinsic and Extrinsic Motivation to Self Directed Learning Readiness (SDLR) then used Chi Square Test.

\section{Result of the Study \\ Description of the Research Location}

This research was conducted in FK-UISU located on STM road, Medan. A minimum sample of the study amounted to 168 people, but samples taken as many as 198 people. Then the data obtained through the questionnaire processed and analyzed.

\section{Descriptive Statistics}

\section{Frequency Distribution of Respondent Characteristics}

In this study, there are some characteristics of respondents namely gender and batch. The frequency distribution of respondent characteristics will be described in more detail as follows:

\section{Frequency Disctribution of Respondents' Gender}

Frequency Distribution of the respondents' gender in presented in the table below: 
Tabel 3.1 - Frequency Distribution of Respondents' Gender

\begin{tabular}{lll}
\hline Gender & Friquency $(\mathrm{F})$ & Percentage $(\%)$ \\
\hline Male & 59 & 29,8 \\
Female & 139 & 70,2 \\
\hline Total & 198 & 100 \\
\hline
\end{tabular}

Table 3.1 shows that female is more dominant with 139 persons $(70,2 \%)$ compared to Male i.e 59 persons $(29,8 \%)$.

\section{Table 3.2 - Frequency Distribution of Respondent Batch}

\begin{tabular}{lll} 
Batch & Frequency $(\mathrm{F})$ & Percentage $(\%)$ \\
\hline 2014 & 82 & 41,4 \\
2015 & 29 & 14,6 \\
2016 & 38 & 19,2 \\
2017 & 49 & 24,8 \\
\hline Total & 198 & 100
\end{tabular}

Table 3.2 shows the percentage of respondents based on their batch. Batch 2014 comes as the highest and the 2015 is the lowest with 29 respondents. This sample proportion is determined through proportional sampling.

\section{Table 3.3 - Frequency Distribution of Instrinsic Motivation}

\begin{tabular}{lcc}
\hline Intrinsic Motivation & Frequency (F) & Percentage (\%) \\
\hline Unmotivated & 88 & 44,4 \\
Motivated & 110 & 55,6 \\
\hline Total & 198 & 100 \\
\hline
\end{tabular}

In table 3.3, it can be seen that students with intrinsic motivation pertained motivated more dominant that is as many as 110 people (55.6\%) than students with intrinsic 
motivation classified as not motivated as many as 88 people $(44.4 \%)$. The frequency distribution of intrinsic motivation is described based on respondent characteristics as follows:

Table 3.4 - Frequency Distribution of Intrinsic Motivation Based on Gender

\begin{tabular}{lllll}
\hline & \multicolumn{3}{l}{ Gender } & \multicolumn{2}{l}{ Female } \\
\cline { 2 - 5 } Intrinsic Motivation & \multicolumn{2}{l}{ Male } & F & $\%$ \\
\cline { 2 - 5 } & F & $\%$ & 64 & 46,0 \\
\hline Unmotivated & 24 & 40,7 & 64 & 54,0 \\
Motivated & 35 & 59,3 & 75 & 100 \\
\hline Total & 59 & 100 & 139 & \\
\hline
\end{tabular}

In table 3.4, it can be seen that male with intrinsic motivation are motivated to be more dominant, as many as 35 people $(59.3 \%)$ compared with unmotivated ie as many as 24 people $(40.7 \%)$, female with intrinsic motivation are also motivated more dominant ie as many as 75 people $(54.0 \%)$ compared with unmotivated ie as many as 64 people $(46.0 \%)$

Table 3.5 - Frequency Distribution of Intrinsic Based on Batch

\begin{tabular}{|c|c|c|c|c|c|c|c|c|c|c|c|c|}
\hline \multirow{3}{*}{$\begin{array}{l}\text { Intrinsic } \\
\text { Motivation }\end{array}$} & \multicolumn{12}{|c|}{ Batch } \\
\hline & \multicolumn{3}{|c|}{2014} & \multicolumn{3}{|c|}{2015} & \multicolumn{3}{|c|}{2016} & \multicolumn{3}{|c|}{2017} \\
\hline & & $\mathrm{F}$ & $\%$ & & $\mathrm{~F}$ & $\%$ & & $\mathrm{~F}$ & $\%$ & & $\mathrm{~F}$ & $\%$ \\
\hline \multirow{2}{*}{ Unmotivated } & & 3 & 39 & & 1 & 48 & & 2 & 57 & & 2 & 40 \\
\hline & 2 & & 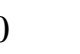 & 4 & & 3 & 2 & &, 9 & 0 & & 8 \\
\hline \multirow{2}{*}{ Motivated } & & 5 & 61 & & 1 & 51 & & 1 & 42 & & 2 & 59 \\
\hline & 0 & & 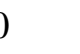 & 5 & & 7 & 6 & &, 1 & 9 & & 2 \\
\hline \multirow{2}{*}{ Total } & & 8 & 10 & & 2 & 10 & & 3 & 10 & & 4 & 10 \\
\hline & 2 & & & 9 & & 0 & 8 & & 0 & 9 & & \\
\hline
\end{tabular}

In table 3.5, it can be seen that batch 2014 students who were motivated more dominantly are as many as 50 people $(61.0 \%)$ compared with unmotivated, that is as many as 32 people (39.0\%), batch 2015 students who motivated slightly more as many as 15 people $51,7 \%$ ) compared with unmotivated that is 14 people $(48,3 \%)$, student batch 2016 unmotivated more dominant that is 22 people $(57,9 \%)$ compared with motivated that is counted 16 person $(42,1 \%)$, and batch 2017 students are motivated 
more dominant as many as 29 people $(59.2 \%)$ compared with unmotivated as many as 20 people $(40.8 \%)$.

\section{Table 3.6 - Frequency Distribution of Extrinsic Motivation}

\begin{tabular}{lll}
\hline $\begin{array}{c}\text { Extrinsic } \\
\text { Motivation }\end{array}$ & Frequency (F) & Percentage (\%) \\
\hline Unmotivated & 98 & 49,5 \\
Motivated & 100 & 50,5 \\
\hline Total & 198 & 100 \\
\hline
\end{tabular}

In table 3.6, it can be seen that students with extrinsic motivation pertained motivated a little more that is as many as 100 people $(50.5 \%)$ while students with extrinsic motivation classified as unmotivated as many as 98 people (49.5\%). Frequency Distribution of extrinsic motivation is described by respondent characteristics as follows:

Table 3.7 - Frequency Distribution of Extrinsic Motivation Based on Gender

\begin{tabular}{lllll}
\hline \multirow{2}{*}{ Extrinsic Motivation } & \multicolumn{3}{l}{ Gender } & \multicolumn{2}{l}{ Female } \\
\cline { 2 - 5 } & \multicolumn{2}{l}{ Male } & F & $\%$ \\
\cline { 2 - 5 } & $\mathrm{F}$ & 40,7 & 74 & 53,2 \\
Unmotivated & 24 & 59,3 & 65 & 46,8 \\
Motivated & 35 & 100 & 139 & 100 \\
\hline Total & 59 &
\end{tabular}

In table 3.7, it can be seen that male with extrinsic motivation are motivated more dominant that is 35 people $(59,3 \%)$ compared with unmotivated that is counted 24 people $(40,7 \%)$ vice versa women with extrinsic motivation belong to unmotivated more dominant that is as much 74 people $(53,2 \%)$ compared with motivated as many as 65 people $(46,8 \%)$. 
Table 3.8 - Frequency Distribution of Extrinsic Motivation Based on Batch

\begin{tabular}{|c|c|c|c|c|c|c|c|c|}
\hline \multirow{3}{*}{$\begin{array}{l}\text { Extrinsic } \\
\text { Motivation }\end{array}$} & \multicolumn{8}{|c|}{ Batch } \\
\hline & \multicolumn{2}{|c|}{2014} & \multicolumn{2}{|c|}{2015} & \multicolumn{2}{|c|}{2016} & \multicolumn{2}{|c|}{2017} \\
\hline & $\mathrm{F}$ & $\%$ & $\mathrm{~F}$ & $\%$ & $\mathrm{~F}$ & $\%$ & $\mathrm{~F}$ & $\%$ \\
\hline Unmotivated & 52 & 63,4 & 10 & 34,5 & 19 & 50,0 & 17 & 34,7 \\
\hline Motivated & 30 & 36,6 & 19 & 65,5 & 19 & 50,0 & 32 & 65,3 \\
\hline Total & 82 & 100 & 29 & 100 & 38 & 100 & 49 & 100 \\
\hline
\end{tabular}

In table 3.8, it can be seen that student batch 2014 that were unmotivated is more dominant, that is as much as 52 people $(63,4 \%)$ compared with motivated ones that is 30 people $(36,6 \%)$, student of batch 2015 which motivated more dominant that is 19 people $(65,5 \%)$ compared with unmotivated as many as 10 people $(34.5 \%)$, batch 2016 students are motivated to have the same number of 19 people $(50.0 \%)$ with unmotivated ie 19 people $(50.0 \%)$, and students batch 2017 which motivated more dominant as many as 32 people $(65,3 \%)$ compared with unmotivated that is as much 17 people $(34,7 \%)$.

Table 3.9 - Frequency Distribution of SDLR

\begin{tabular}{lll}
\hline SDLR & Frequency (F) & Percentage (\%) \\
\hline Poor SDLR & 99 & 50,0 \\
Good SDLR & 99 & 50,0 \\
\hline Total & 198 & 100 \\
\hline
\end{tabular}

In table 3.9, it can be seen that students with SDLR that are classified "good" has the same number of 99 people $(50.0 \%)$ with SDLR students are "poor" as many as 99 people $(50.0 \%)$. Frequency Distribution SDLR is described based on respondent characteristics as follows: 
Table 3.10 - Frequency Distributionof SDLR Based on Gender

\begin{tabular}{lllll}
\hline \multirow{2}{*}{ SDLR } & \multicolumn{3}{l}{ Gender } & \multicolumn{2}{c}{ Female } \\
\cline { 2 - 5 } & \multicolumn{3}{l}{ Male } & \multicolumn{3}{c}{} \\
\cline { 2 - 5 } & $\mathrm{F}$ & 39,0 & 76 & 54,7 \\
\hline Poor SDLR & 23 & 61,0 & 63 & 45,3 \\
Good SDLR & 36 & 100 & 139 & 100 \\
\hline Total & 59 & & & \\
\hline
\end{tabular}

In table 3.10, it can be seen that male with SDLR are classified as more dominant, ie as many as 36 people $(61.0 \%)$ compared with bad SDLR that is as many as 23 people (39.0\%) otherwise female with SDLR classified as more dominant as 76 (54.7\%) compared to the good SDLR that is as many as 63 people (45.3\%).

Table 3.11 Frequency Distribution of SDLR Based on Batch

\begin{tabular}{|c|c|c|c|c|c|c|c|c|}
\hline \multirow{3}{*}{ SDLR } & \multicolumn{8}{|c|}{ Batch } \\
\hline & \multicolumn{3}{|c|}{2014} & \multicolumn{2}{|c|}{2015} & \multicolumn{2}{|c|}{2016} & 2017 \\
\hline & & $\%$ & & ] & & $\%$ & & $\%$ \\
\hline Poor & & 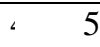 & & & & 5 & & 3 \\
\hline SDLR & 2 & 1,2 & 9 & 5,5 & ( & 2,6 & 8 & 6,7 \\
\hline Good & & . 4 & & & & 4 & & 6 \\
\hline SDLR & 0 & 8,8 & 0 & 4,5 & 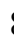 & 7,4 & 1 & 3,3 \\
\hline Totol & & $\vdots \quad 1$ & & & & 1 & & ‘ 1 \\
\hline lotal & 2 & 00 & 9 & 00 & & 00 & 9 & 00 \\
\hline
\end{tabular}

In table 3.11 it can be seen that batch 2014 students with SDLR classified as "poor" as many as 42 people (51.2\%) compared to the "good" SDLR that is as many as 40 people (48.8\%), batch 2015 students with SDLR classified as more dominant that is 19 people $(65,5 \%)$ compared to SDLR either as many as 10 people $(34,5 \%)$, batch student of 2016 with SDLR classified as a little bit more as many as 20 people $(52,6 \%)$ compared to SDLR either as many as 18 people (47.4\%), and batch 2017 students with SDLR both more dominant as many as 31 people $(63.3 \%)$ compared to bad SDLR that is as many as 18 people $(36.7 \%)$. 


\section{Hypothesis Test \\ The Correlation Between Intrinsic Motivation and Self Directed Learning Readiness}

The significance level of the test is, $p=0,001$, so it can be concluded that intrinsic motivation has a significant correlation to the Self Directed Learning Readiness on undergraduate students of FK of Islamic University of North Sumatera University in 2017. Description of hypothesis test can be observed at Table 4.1 below:

Table 4.1 The Correlation Between Intrinsic Motivation and Self Directed Learning Readiness (SDLR)

\begin{tabular}{|c|c|c|c|c|c|c|c|c|}
\hline \multirow{3}{*}{$\begin{array}{l}\text { Intrinsic } \\
\text { Motivation }\end{array}$} & \multicolumn{4}{|c|}{ SDLR } & \multirow{2}{*}{\multicolumn{2}{|c|}{ Total }} & \multirow{3}{*}{$P R$} & \multirow{3}{*}{$\begin{array}{r}P \\
\text { value }\end{array}$} \\
\hline & \multicolumn{2}{|c|}{ Poor SDLR } & \multicolumn{2}{|c|}{$\begin{array}{l}\text { Good } \\
\text { SDLR }\end{array}$} & & & & \\
\hline & $\mathrm{F}$ & $\%$ & $\mathrm{~F}$ & $\%$ & F & $\%$ & & \\
\hline Unmotivated & 56 & 28,3 & 32 & 16,2 & 88 & 44,4 & & \\
\hline Motivated & 43 & 21,7 & 67 & 33,8 & 110 & 55,6 & $1,0<0$ & 0,001 \\
\hline Total & 99 & 50 & 99 & 50 & & & & \\
\hline
\end{tabular}

\section{The Correlation Between Extrinsic Motivation and Self Directed Learning Readiness}

The significance test obtained $\mathrm{p}=0.000$, so it can be concluded that extrinsic motivation has significant correlation to Self Directed Learning Readiness on undergraduate students FK-UISU in 2017. Description of hypothesis test can be observed in table 4.2 below:

Table 4.2 Correlation Between Extrinsic Motivation andSelf Directed Learning Readiness (SDLR)

\begin{tabular}{|c|c|c|c|c|c|c|c|c|}
\hline \multirow{3}{*}{$\begin{array}{l}\text { Extrinsic } \\
\text { Motivation }\end{array}$} & \multicolumn{4}{|c|}{ SDLR } & \multirow{2}{*}{\multicolumn{2}{|c|}{ Total }} & \multirow{3}{*}{$R^{P}$} & \multirow{3}{*}{$\begin{array}{r}P \\
\text { value }\end{array}$} \\
\hline & \multicolumn{2}{|c|}{ Poor SDLR } & \multicolumn{2}{|c|}{ Good SDLR } & & & & \\
\hline & $\mathrm{F}$ & $\%$ & $\mathrm{~F}$ & $\%$ & $\mathrm{~F}$ & $\%$ & & \\
\hline Unmotivated & 64 & 32,3 & 34 & 17,2 & 98 & 49,5 & 1,86 & 0,00 \\
\hline Motivated & 35 & 17,7 & 65 & 32,8 & 100 & 50,5 & 6 & 0 \\
\hline
\end{tabular}




\begin{tabular}{lllll|l|l}
\hline Total & 99 & 50 & 99 & 50 & & \\
\hline
\end{tabular}

\section{Discussion}

\section{Frequency Distribution of Respondent Characteristics}

In this study the characteristics of research respondents are based on gender and batch. Based on the results of the research in Table 3.1 on Frequency Distribution of gender of respondents, female are more dominant as many as 139 people $(70.2 \%)$ than men ie 59 people (29.8\%). This is in accordance with the entire students at the Faculty of Medicine, University of Islam Sumatera Utara 2017 which is more dominated by female.

Based on the results of the research in table 3.2 on Frequency Distribution batch of respondents, batch 2014 as many as 82 people (41.4\%), batch 2015 as many as 29 people (14.6\%), batch 2016 counted 38 people (19.2\%), and batch 2017 as many as 49 people (24.8\%).

\section{Frequency Distribution of Intrinsic Motivation}

Based on the result of research in table 3.3 about Frequency Distribution of intrinsic motivation, student with intrinsic motivation pertained motivated more dominant that is 110 people $(55,6 \%)$ than student with intrinsic motivation classified as unmotivated that is 88 people $(44,4 \%)$. Based on the results of the research in Table 4.4 on Frequency Distribution of intrinsic motivation based on gender, male respondents who motivated more dominant were as many as 35 people (59.3\%) compared to unmotivated male respondents ie as many as 24 people (40.7\%). Similarly, male respondents, female respondents who are motivated are also more dominant as many as 75 people $(54.0 \%)$ compared with unmotivated female respondents ie as many as 64 people $(46.0 \%)$. When compared, the percentage of male respondents who are motivated (59.3\%) is higher than the female respondents who are motivated (54.0\%).

Based on the research results in Table 3.4 on Frequency Distribution of intrinsic motivation based on batches, batch of 2014 students who motivated had the highest percentage of $61.0 \%$, followed by batch 2017 students with 59.2\% percentage, then batch 2015 students with $51.7 \% \%$, and the lowest batch student 2016 with a percentage of $42.1 \%$. 


\section{Frequency Distribution of Extrinsic Motivation}

Based on the results of the research in Table 3.6 on Frequency Distribution of extrinsic motivation, students with extrinsic motivation are motivated a little more as many as 100 people $(50.5 \%)$ than students with extrinsic motivation classified as unmotivated that is 98 people $(49.5 \%)$. Same as intrinsic motivation, the percentage of students with extrinsic motivation is motivated in this study is still quite low compared to the research conducted by Liliswanti at the Faculty of Medicine, University of Lampung in 2013, which is $91.9 \%$ (148 people) of extrinsic motivation is high, 7, 5\% (12 people) are moderate and $0.6 \%$ ( 1 person) is low (Liliswanti et. al, 2015). However, the percentage of students with extrinsic motivation is motivated in this study is higher when compared with Roni's research at the Faculty of Medicine, University of Batam in 2016 with the number of students with motivated extrinsic motivation as much as $32.9 \%$ (69 people) and unmotivated 67 students, 1\% (141 people).Based on the results of the research in Table 3.7 on Frequency Distribution of extrinsic motivation based on gender, male respondents who motivated more dominant are as many as 35 people $(59.3 \%)$ compared to unmotivated male respondents as many as 24 people $(40.7 \%)$. In contrast to male respondents, unmotivated female respondents were more dominant, 74 $(53.2 \%)$ than female respondents who were motivated by 65 people $(46.8 \%)$. When compared, the percentage of male respondents who are motivated $(59.3 \%)$ is higher than the female respondents who are motivated $(46.8 \%)$.

Based on the results of the research in Table 3.8 on Frequency Distribution of extrinsic motivation that based on batches, batch of 2015 students who motivated had the highest percentage of $65.5 \%$, followed by batch 2017 students with $65.3 \%$ percentage, then batch 2016 students with $50.0 \%$, and the lowest student batch 2014 with percentage $36.6 \%$.

\section{Frequency Distribution Self Directed Learning Readiness}

Based on the results of the research in Table 3.9 on Frequency Distribution of Self Directed Learning Readiness (SDLR), students with SDLR have the same number of 99 people (50\%) with SDLR students that are bad is as many as 99 people (50\%).

The percentage of students with SDLR is good in this study, that is higher than the research of Roni at the Faculty of Medicine, University of Batam in 2016 with the number of students with SDLR is good as much as $44.8 \%$ (94 people) and quite poor as much as 55.2\% (116 people) (Roni, 2016). And Akbar's research at the Faculty of Medicine, Gadjah Mada University 2014, the number of students with SDLR is high as much as $17.3 \%$ (78 people) and classified as many as $82.7 \%$ (373 people) (Akbar, 2014).

Int.J. Hum. Soc. Dev. Res. 
Based on the results of the research in Table 3.10 on Frequency Distribution of SDLR based on gender, male respondents with SDLR both more dominant that is as many as 36 people $(61.0 \%)$ compared to male respondents with bad SDLR that is as many as 23 people (39.0\%). In contrast to male respondents, female respondents with bad SDLR were more dominant as many as 76 people (54.7\%) compared with female respondents with SDLR either as many as 63 people (45.3\%). When compared, the percentage of male respondents with good SDLR (61.0\%) was higher than that of female respondents with poor SDLR (45.3\%).

Based on the results of the research, in Table 3.11Frequency Distribution SDLR based on batches, batch of 2017 students with SDLR both have the highest percentage of $63.3 \%$, followed by batch 2014 students with $48.8 \%$ percentage, then batch 2016 students with a percentage of $47.4 \%$, and the lowest in 2015 batch students with a percentage of $34.5 \%$.

\section{The Correlation Between Intrinsic Motivation and Self Directed Learning}

\section{Readiness}

Based on the result of research in table 4.1 about intrinsic motivation relationship with Self Directed Learning Readiness (SDLR), by using Chi-square hypothesis test, it is obtained that $\mathrm{p}$ value $=0.001$ which means there is a significant correlation between intrinsic motivation with Self Directed Learning Readiness (SDLR) $\mathrm{p}<0.05$. There was a significant correlation between intrinsic motivation and Self Directed Learning Readiness (SDLR), hypothesis test result on that research is $p=0.0004$. Research conducted by Akbar also get the same result that there is significant correlation between intrinsic motivation with Self Directed Learning Readiness (SDLR), result of hypothesis test at that research that is $\mathrm{p}=0,0015$.

\section{The Correlation Between Extrinsic Motivation and Self Directed Learning}

\section{Readiness}

Based on the results of the research in Table 4.2 about extrinsic motivation relationship and Self Directed Learning Readiness (SDLR), by using Chi-square hypothesis test obtained $\mathrm{p}$ value $=0,000$ which means there is a significant relationship between extrinsic motivation with Self Directed Learning Readiness (SDLR) p <0.05. The result of this research is similar to Roni's research that there is a significant correlation between extrinsic motivation with Self Directed Learning Readiness (SDLR), the result of hypothesis test on the research is $p=0.0004$. Research conducted by Malkawi also get the same result that there is significant correlation between 
extrinsic motivation with Self Directed Learning (SDLR), result of hypothesis test on that research that is $\mathrm{p}=0,017$ (Malkawi, 2015).

\section{Conclusions}

Based on the results of research in FK-UISU in June 2017 - January 2018, then this research obtained the following conclusions:

1. The intrinsic motivation of FK-UISU undergraduate medical students in 2017 is classified as motivated more $(55,6 \%)$ than unmotivated $(44,4)$. Intrinsic motivation of undergraduate students of UISU undergraduate program in 2017 based on gender, motivated men $(59.3 \%)$ are higher than women who are motivated $(54,0 \%)$. The intrinsic motivation of medical undergraduate students of FK-UISU in 2017 is based on batches, batch 2014 students who are motivated (61.0\%) of the highest percentage and batch 2016 students are motivated $(42.1 \%)$ the lowest percentage.

2. Extrinsic motivation of medical undergraduate students of FK-UISU in 2017 is classified as motivated only slightly more $(50.5 \%)$ than unmotivated $(49.5 \%)$. Extrinsic motivation of medical undergraduate students of FK-UISU 2017 based on gender, motivated men (59.3\%) higher percentage than motivated women (46.8\%) Extrinsic motivation of FK-UISU undergraduate students in 2017 based on batch, batch 2015 students who are motivated $(65.5 \%)$ of the highest percentage and batch 2014 students are motivated $(36.6 \%)$ the lowest percentage.

3. Self Directed Learning Readiness of FK-UISU undergraduate students in 2017 is good (50\%) has the same percentage as the bad (50\%). Self Directed Learning Readiness of FK-UISU undergraduate students in 2017 based on batches, batch 2017 students with good SDLR $(63.3 \%)$ of the highest percentage and batch 2016 students with good SDLR (34.5\%) of the lowest percentage. Self Directed Learning Readiness of FK-UISU undergraduate students in 2017 based on batches, batch 2017 students with good SDLR (63.3\%) of the highest percentage and batch 2016 students with good SDLR (34.5\%) of the lowest percentage.

4. There is a significant relationship $(\mathrm{p}=0.001)$ between intrinsic motivation and SDLR of FK-UISU undergraduate medical students in 2017. There is a significant relationship ( $p$ $=0,000$ ) between extrinsic motivation and SDLR of FK-UISU undergraduate medical students in 2017.

\section{Disclosure statement}

No potential conflict of interest was reported by the authors. 


\section{References and notes:}

Muhammad Arif, Gerry Silaban, Isyatun Mardiah Syahri, 'Analisa Potensi Bahaya dengan Menggunakan Metode Job Safety Analysis (JSA) pada Proses Coal Chain di Pertambangan Batubara X Tahun 2014",

https://www.osha.gov/Publications/osha3071.pdf, accessed March 6, 2019.

James Roughton, Nathan Crutchfield, " Job Hazard Analysis: A guide for voluntary compliance and beyond",

Swartz George, Job hazard analysis . Professional Safety; Des Plaines Vol. 47, Iss. 11, (Nov 2002): pp.27-33.

John Ridley and John Channing, ,'Safety at Work "' Sixth edition

https://www.yamata.com.tr/en/projects/propane-dehydrogenation-unit-pdh-tobolsk/, accessed March 6, 2019.

https://www.rit.edu/ w-outrea/OSHA/documents/Module2/M2_JHA.pdf, accessed March 6, 2019.

Charles D. Reese, 'Occupational Health and Safety Management: A Practical Approach', https://www.safetyinfo.com/job-safety-analysis-jsa-safety-index/, accessed March 6, 2019.

\section{Contact Information}

E-mail: irpan@yahoo.com 